\title{
THE STATUS OF S-BAND RF GUN SYSTEM AT SRRC
}

\author{
C. H. Ho ${ }^{\#}$, S. S. Chang, J. P. Chiou, M. J. Horny, K. T. Hsu, S. Y. Hsu, \\ J. Y. Hwang, K. K. Lin, Y. L.Tsai, SRRC, Hsinchu, TAIWAN
}

\section{Abstract}

An S-band $\mathrm{rf}$ gun system is being developed at SRRC (Synchrotron Radiation Research Center), Taiwan. An XK-5 klystron (2856 MHz) and a TH2100A klystron $(2998 \mathrm{MHz})$ will be used as the microwave sources. The modulator systems for both klystrons are being constructed at SRRC. The status of the rf gun and modulator systems are reported.

\section{INTRODUCTION}

Through the international collaboration on the X-band if gun research project between SRRC and UC Davis [1-2], SRRC had acquired a lot of high power S-band rf components, including the XK-5 klystron (2856 MHz), TWT driver, and PFN components. For the short-term goal, we are going to assemble these components for delivering approximately $16 \mathrm{MW}$ rf power by the end of year 1999. For the long-term goal, we are constructing a high power modulator similar to that for the SRRC booster linac system $(2998 \mathrm{MHz})$, which is able to deliver 35 MW rf power. The completion date is set to be sometime in the year 2000. On successful commissioning of this home made modulator, it means our maintenance ability for the booster linac will be highly improved and the high power technology at SRRC be elevated to a new level. This in turn will definitely reduce the possibility for down time of our booster linac. On the other hand, it could also serve as the high power if source for the rf gun research project when the booster is in normal operation. The main application of the rf gun at SRRC aims for the IRFEL. (Infra Red Free Electron Laser) in the near future. For a quick start, we are going to build a single cell Sband $(2856 \mathrm{MHz})$ thermionic rf gun first. We expect to commission this gun with the XK-5 klystron modulator system very soon.

\section{COLD TEST OF THE RF GUN}

We have designed a single cell S-band (2856 MHz) rf gun using the code URMEL [3]. The cavity is a simple pill box type with $80.36 \mathrm{~mm}$ diameter and $32.50 \mathrm{~mm}$ cell length. A flat copper cathode with $15.50 \mathrm{~mm}$ diameter was used for test purpose. A prototype copper cavity had been fabricated and brazed. Figure 1 shows the assembly drawing of the prototype gun. Three stages of vacuum brazing corresponding to three different melting

\footnotetext{
Work supported in part by the National Science Council (Taiwan) under contract No. NSC88-2112-M-213-007.

"Email: chh@srrc.gov.tw
}

temperatures of brazing alloys (from WESGO company) were used to allow the fabrication of various components.

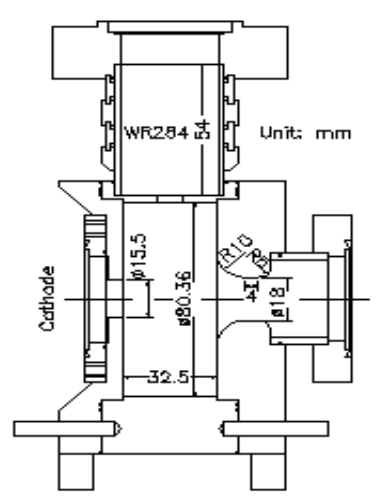

Figure 1: Assembly drawing of the gun cavity.

The first stage used 35/65 Au/Cu (35\% Gold and 65\% Copper) as the brazing alloy (melting temperature: 1010 $\left.{ }^{\circ} \mathrm{C}\right)$ to braze the following three items: (1) WR 284 OFHC waveguide and SUS 304 Merdinian flange (female), (2) Copper cathode plate and 35 CF flange (SUS 304), and (3) Copper plate and SUS 304 straight vacuum tube (1.5" O.D.) for electron beam exit. The second stage used 50/50 $\mathrm{Au} / \mathrm{Cu}$ as the brazing alloy (melting temperature: $970^{\circ} \mathrm{C}$ ) to braze the following two items: (1) WR 284 waveguide and the surrounding enforcement copper bars (to prevent the waveguide deformation when evacuated), and (2) Cavity body, cathode plate, and beam exit plate. The last stage used Palcusil $15(65 \% \mathrm{Ag}, 20.3 \% \mathrm{Cu}$ and $14.7 \% \mathrm{Pd})$ as the brazing alloy (melting temperature: $900^{\circ} \mathrm{C}$ ) to braze the cavity body and WR 284 waveguide together. After brazing, the cavity was vacuum tested using a Helium leak detector and found to be Helium leak tight to better than $10^{-9}$ standard c.c./sec.

The experimental arrangement for the bead pull measurement is shown in Fig. 2. A machineable ceramic (Aluminium Oxide) bead with $2 \mathrm{~mm}$ diameter was used as an axial cavity perturbation. The bead was drilled using an Nd:Yag laser, and supported by a nylon string with $0.1 \mathrm{~mm}$ diameter. Two lab jacks were used to support and adjust the height of the gun body. One translator stage was used for the horizontal alignment and the other translator stage was used to pull the gun body so that we were able to position the ceramic bead at any position along the longitudinal axis of the cavity. The movement resolution of the translator stage is $0.01 \mathrm{~mm}$, while we only move the gun body along the longitudinal axis in 
steps of $0.5 \mathrm{~mm}$. The bead-pull measurement result is shown in Fig. 3. We also show the consistency of the measured data with an URMEL calculation.

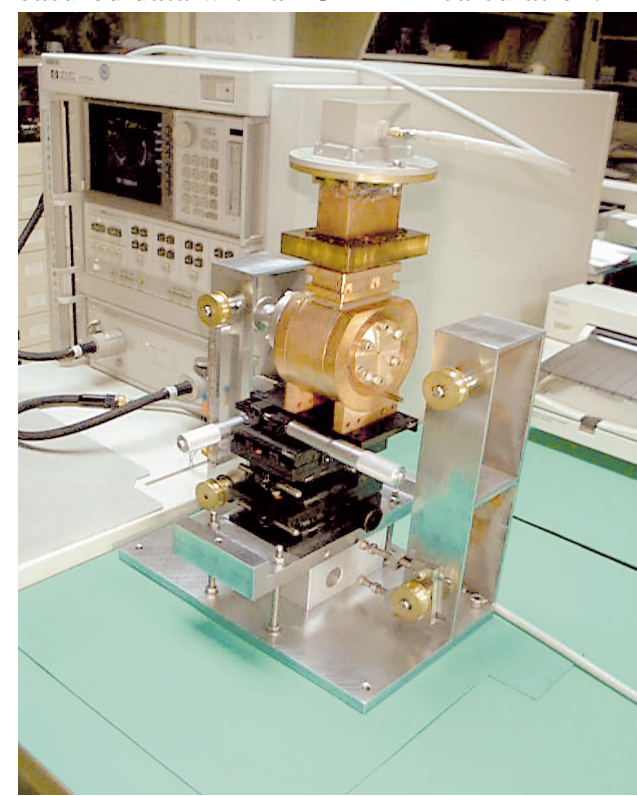

Figure 2: Bead - pull measurement setup.

An elliptical rf coupling iris was gradually enlarged to the length of the major semi-axis being $13.25 \mathrm{~mm}$ and the minor semi-axis being $4.90 \mathrm{~mm}$ before brazing. The coupling coefficient was found to shift from 0.8 (before brazing) to 2.1 (after brazing). The measured unloaded quality factor is 6740 after brazing.

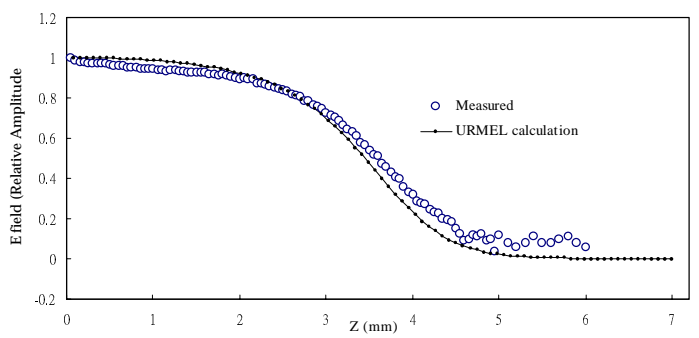

Figure 3: Longitudinal E - field profile on axis.

\section{THE PFN TEST STAND}

In order to provide necessary rf power in feeding the 2856 $\mathrm{MHz}$ rf gun cavity, a modulator was designed and built to power the XK-5 SLAC klystron. The circuit diagram of this S-band klystron modulator is given in figure 4.

The Spellman SR-6 DC charging power supply (PS) is used for testing purpose and is capable of delivering $0.2 \mathrm{~A}$ output current at $30 \mathrm{kV}$ and up to $50 \mathrm{kV}$ at smaller current. The CX1154 thyratron switch holds the high voltage at capacitors of pulsed forming network (PFN).

Protection of the DC PS and thyratron is accomplished with a charging inductor and diodes. PFN inductors are made of copper tube with $6 \mathrm{~mm}$ in diameter. Inductance tuning at nominal charging voltage is done by adjusting the position of short circuit clamp associated with every inductor. The match resistor reduces power reflected from the circuit load. As the thyratron is triggered, the pulsed current from the PFN is fed into XK-5 klystron such that the low power driving rf signal can be amplified up to 16 MW [4]. Calculated current pulse from the PFN is optimized for the indicated load resistor and is shown in figure 5. Table 1 gives the technical specification of the designed modulator.

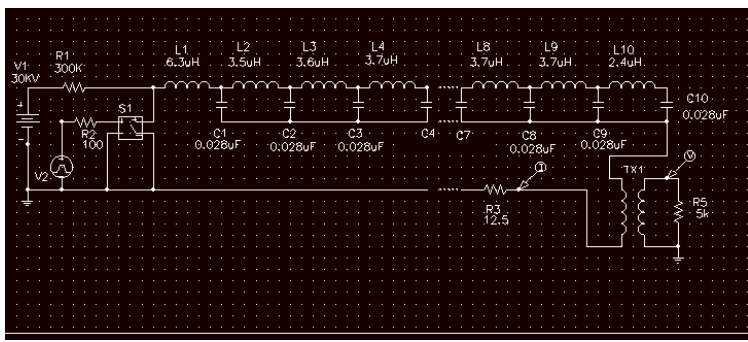

Figure 4: The circuit diagram of this S-band klystron modulator. It consists of 10 sections of LC circuit. Every individual inductor is tuned to obtain the required flattop pulse.
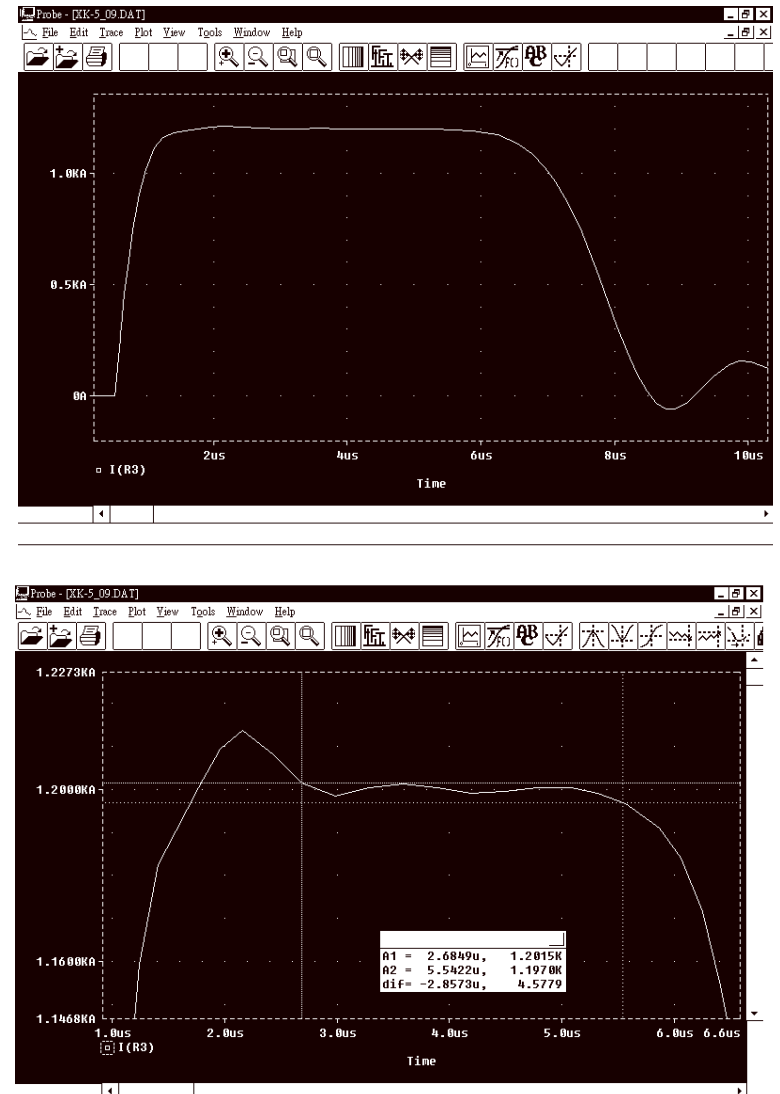

Figure 5: On top of the figure, the calculated current pulse from the PFN is optimized for the indicated load resistor. The expanded view of the flattop region is shown in the lower part. It indicates that a flattop with $0.5 \%$ amplitude variation over $3 \mu \mathrm{sec}$ is estimated.

Figure 5 shows the PFN current feeding into the XK-5 klystron. The top of the figure gives the current pulse and the bottom shows its flatness is $0.5 \%$ over $3 \mu \mathrm{sec}$ range. 
Table I. Technical specification of S-band modulator Design parameter

PFN charging voltage (nominal) $30 \quad \mathrm{kV}$

Output voltage (nominal) $\quad 15 \mathrm{kV}$

Repetition rate (nominal) $\quad 10 \mathrm{~Hz}$

Pulse width $(50 \%) \quad 7 \quad \mu$ sec

Rise time $(10-90 \%) \quad<1 \quad \mu$ sec

Fall time $(10-90 \%) \quad<2 \quad \mu \mathrm{sec}$

Pulse flatness (for $3 \mu \mathrm{sec}$ ) $\quad<0.5 \%$

Number of sections

10

A preliminary test run of the constructed PFN system is given in figure 6 . It gives the voltage pulse shape at the load resistor. This test run was done at charging voltage of $10 \mathrm{kV}$. Considering the flatness requirement, further adjustment of individual inductance at every section is necessary to improve the flatness of the pulse. It also indicates that adjusting the match resistor is needed to reduce the bump signal at the pulse tail.

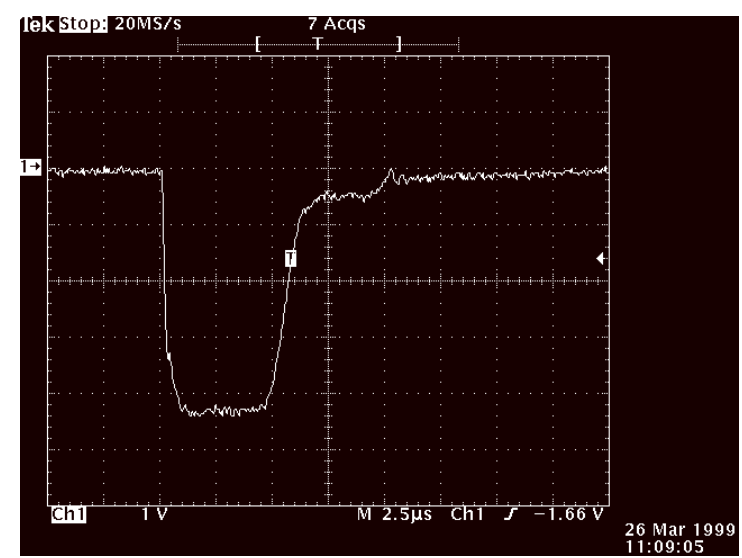

Figure 6: Preliminary test result of the PFN output voltage pulse at the load resistor. The charging voltage of this test is $10 \mathrm{kV}$.

\section{SUMMARY}

An S-band rf gun system is being developed at SRRC. Both $2856 \mathrm{MHz}$ and $2998 \mathrm{MHz}$ systems are considered. The rf cavity and the associated klystron modulator are under construction and fine tuning. The measured results on cavity E - field profile and modulator output pulse shape are compared with the calculation expectation. Tuning of each subsystem in further optimizing their performance is expected.

\section{REFERENCES}

[1] C. H. Ho, W. K. Lau, T. T. Yang,J. Y. Hwang, S. Y. Hsu, Y. C. Liu, G. P. Le Sage, F. V. Hartemann, and N. C. Luhmann, Jr., "The Design and Fabrication of an X-Band RF Gun", AIP Conf. Proc. 398 for the Seventh Workshop on Advanced Accelerator Concepts (Lake Tahoe, California, 1996), p. 705.

[2] E. C. Landahl,, F. V. Hartemann, G. P. Le Sage, W. E. White, H. A. Baldis, C. V. Bennett, J. P. Heritage, N. C. Luhmann, Jr., and C. H. Ho, "Phase Noise Reduction and Photoelectron Acceleration in a High-Q RF Gun", IEEE Transaction on Plasma Science, Special Issue on High Power Microwave Generation, Vol. 26, No. 3, pp. 814-824 (June 1998).

[3] U. Laustroer, U. van Rienen and T. Weiland, "URMEL and URMEL-T User Guide,” DESY M-87-03 (1987).

[4] S. Park and G. LeSage, private communication. 